Supporting Information

\title{
Contactless and Simultaneous Measurement of Water and Acid Contaminations in Oil Using a Flexible Microstrip Sensor
}

Qiannan Xue ${ }^{\dagger, \S, *}$, Xiecheng Tang ${ }^{\dagger, \downarrow}, \S$, Yanna $\mathrm{Li}^{\dagger}{ }^{\dagger} \S$, Haitao Liu ${ }^{\ddagger}$, Xuexin Duan ${ }^{\dagger}, *$ † State Key Laboratory of Precision Measuring Technology \& Instruments, School of Precision Instruments and Optoelectronics Engineering, Tianjin University, Tianjin 300072, China;

$\$$ Sino-european Institute of Aviation Engineering, College of Electronic Information and Automation, Civil Aviation University of China, Tianjin 300300, China 


\section{S1. The oil sample preparing method}

The acidity of oils depends on the amount of both weak acid, e.g. carboxylic acids, and strong acids, e.g. nitric and sulphuric acid. Here, nitric acid was used to prepare oil samples with different acid values. The oil samples were prepared by progressively adding nitric acid drops ( $30 \%$ concentration) into the fresh hydraulic oil, with the acid value of $0.2-3.0 \mathrm{mg} \mathrm{KOH} / \mathrm{g}$. Ultrapure water, represents the water content in oil, was added into the fresh hydraulic oil with the mass fraction of $0.05 \%-4.5 \%$. To ensure the acid or water mixes well in the oil, the oil was constantly stirred while the acid drops or water drops were added into the oil for 15 min before the detection. The preparing method of oil sample and the meaning of acid value are described in detail in literature. ${ }^{1}$ 


\section{S2. The total capacitance three kinds of interdigital microstrip sensor}

In this paper, three kinds of interdigital microstrip structures have been desinged, including interdigital, circle spiral-based and squre spiral-based microstrip sensors (Figure S1a, b, and c). For interdigital microstrip structure, the capacitance of the sensor is determined by the summing of unit cell capacitance. ${ }^{2}$ It can be calculated as Equation (s1)

$$
C_{\text {inter }}=C_{t} N L
$$

Where $\mathrm{C}_{\text {inter }}$ is the total capacitance of interdigital microstrip structrue, $\mathrm{C}_{t}$ is the capacitance of each unit cell, $\mathrm{N}$ is the number of the unit and $\mathrm{L}$ is the length of interditital microstrip. As shown from Figure S1d, it can be calculated as Equation (s2-s4).

$$
\begin{aligned}
& C_{t}=C_{\text {sam }}+C_{\text {gap }}+C_{\text {sub }} \\
& C_{\text {sam }}+C_{\text {sub }}=\varepsilon_{0} \frac{\left(\varepsilon_{\text {sam }}+\varepsilon_{\text {sub }}\right)}{2} \frac{\mathrm{K} \sqrt{1-\delta^{2}}}{\mathrm{~K} \delta} \\
& C_{\text {gap }}=\varepsilon_{0} \varepsilon_{\text {sam }} \frac{h}{w}
\end{aligned}
$$

$\mathrm{C}_{\text {sam }}$ is the capcitance of sample undertest. $\mathrm{C}_{\mathrm{gap}}$ is the capacitance of between the micorstrips. $\mathrm{C}_{\text {sub }}$ is the capcitance of the substrate. Furthermore, $\varepsilon_{0}$ is the dielectric constant $\left(8.854 \times 10^{-12}\right.$ $\mathrm{F} / \mathrm{m}), \varepsilon_{\text {sam }}$ is the dielectric material upper the microstrips, $\varepsilon_{g a p}$ is the dielectric material between the microstrips, and $\varepsilon_{\text {sub }}$ is the dielectric constant of the substrate. $\mathrm{K} \sqrt{1-\delta^{2}}$ and $\mathrm{K} \delta$ are the elliptic integrals of modulus $\sqrt{1-\delta^{2}}$ and $\delta$ respectively. $\delta$ is the parameter related to the width and spacing of microstrip antenna. $\mathrm{h}$ is the thickness of the metal layer and $\mathrm{w}$ is the width of the microstrip line. For interdigital microstrip sensor, $\delta=\mathrm{w} / \mathrm{b} .^{3}$

For spiral-based microstrip sensor, including squre and circle, the capcitance of microstrip sensor, $\mathrm{Ct}$, is still in accordance with Formula (s2-s4). Here, the value of $\delta$ is as follows:

$$
\delta=\frac{g-\Delta}{w+g+\Delta}
$$


The line capacitance which is taken into account as an increment $2 \Delta$ in the strip width, relating to the film thickness. ${ }^{4}$ In this paper, the gap between two strips, g, is equal to $1 / 2 \mathrm{w}$.

In summary, the capacitance values of the three microstrip line sensors based on interdigital structure are directly related to the dielectric constant of the sample solution applied on them, and are also related to their linewidth, configuration and thickness of the metal layer.

a

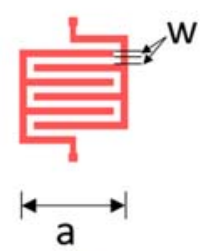

b

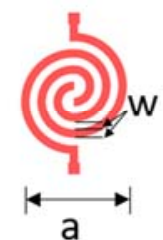

C

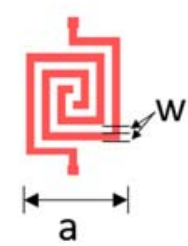

d

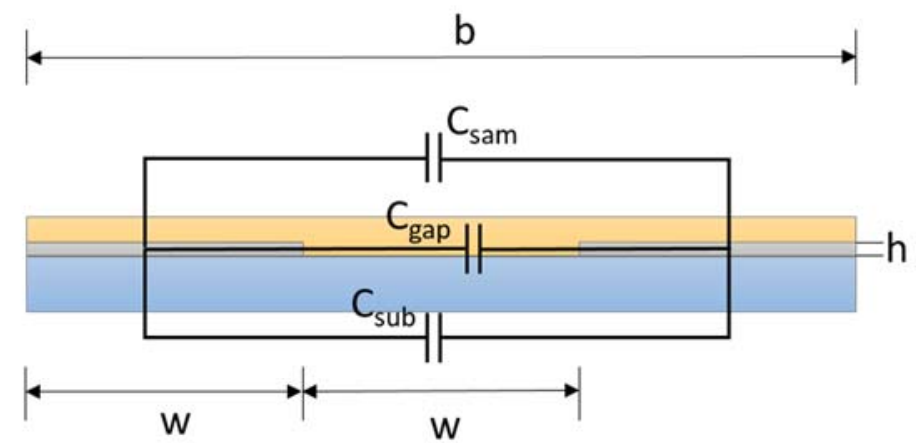

e

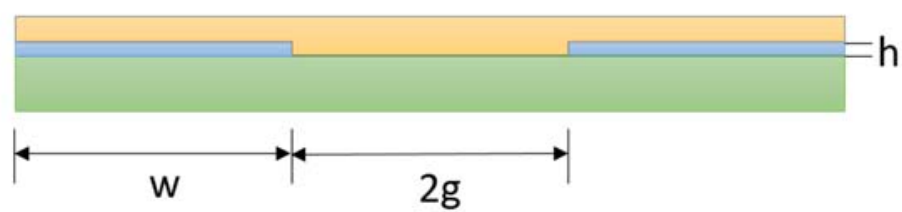

Figure S1. the design of interdigital microstrip sensor a); circle spiral-based microstrip sensor b); squre spiral-based microstrip sensor c); cross section of unit cell representation of interdigital microstrip sensor d) and spiral-based microstrip sensor e). 


\section{S3. Circle spiral-based and interdigital microstrip sensors for water content and acid}

\section{value detection}

In order to characterize the ability of circle spiral-based and interdigital microstrip sensor to detect acid value in water-containing oil samples, the corresponding transission coefficient signal were recorded by applying different water content and acid value oil samples respectively (Figure S2).

a

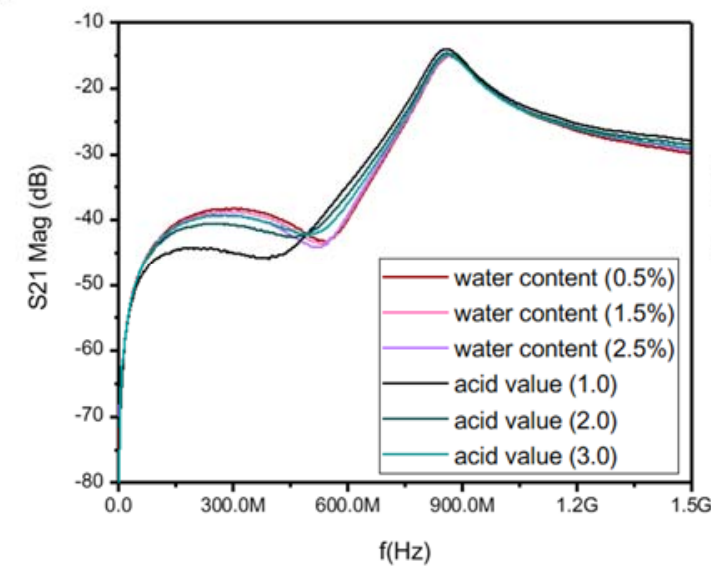

b

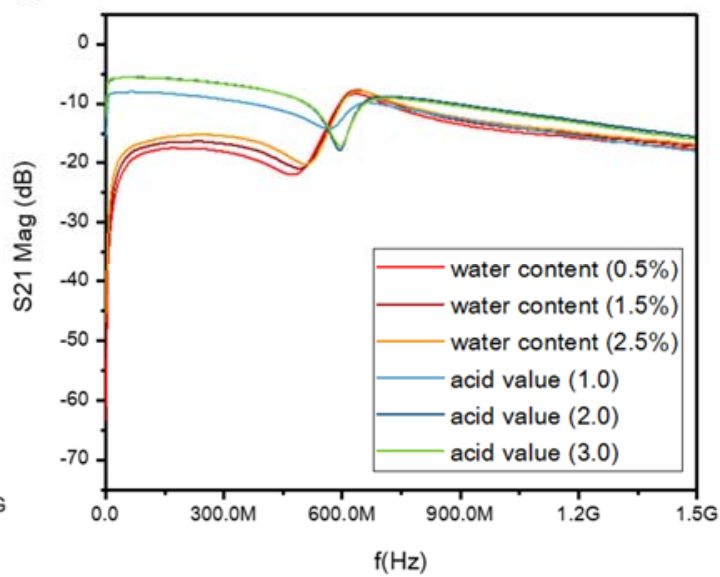

Figure S2. the magnitude of transmission coefficient with interdigital microstrip sensor for detecting water content (0.5-2.5\%) and oil acid value (1-3 $\mathrm{mgKOH} / \mathrm{g}) \mathrm{a})$; the magnitude of transmission coefficient with circle spiral-based microstrip sensors for detecting water content (0.5-2.5\%) and oil acid value (1-3 $\mathrm{mgKOH} / \mathrm{g}) \mathrm{b}$ ). 


\section{S4. The response of square spiral-based, circle spiral-based and interdigital microstrip sensors for different water contents and acid values}

Different water content $(0.5 \%, 1.5 \%, 2.5 \%, 3.5 \%, 4.5 \%)$ in oil samples were detected by the microstrip sensors based on square spiral-based, circle spiral-based and interdigital structures respectively. The peak values of reflection coefficient spectrum were recorded and Figure S3a shows the corresponding relationship between $\mathrm{S}_{11}$ magnitude response and water content. Then, $\mathrm{S}_{11}$ magnitude spectrums were recorded of three kinds of microstrip sensors for different acid value $(0.5,1.0,1.5,2.0,2.5,3.0 \mathrm{mgKOH} / \mathrm{g})$ respectively (Figure S3b). For circular spiral-based and interdigital microstrip sensors, the results show that different water content and acid value can both cause the response changes, so their $\mathrm{k}_{\mathrm{w} 1}$ values are very low. For the square spiralbased microstrip sensor, the response to water content has high sensitivity, and it is not sensitive to the change of acid value. The value of $\mathrm{k}_{\mathrm{w} 1}$ is ten times that of the other two sensors. Figure S4 shows the transmission coefficient for different water content and acid value at $10 \mathrm{MHz}$ frequency. It shows that the responses based on three kinds of interdigital shape changed with water content and acid value, but the response sensitivities are different. Table 1 lists the sensitivities and corresponding values of $\mathrm{k}_{\mathrm{w} 1}$ and $\mathrm{k}_{\mathrm{w} 2}$. The above results show that the square spiral-based microstrip sensor has the best selectivity and better sensitivity for the detection of water content and acid value. 
a
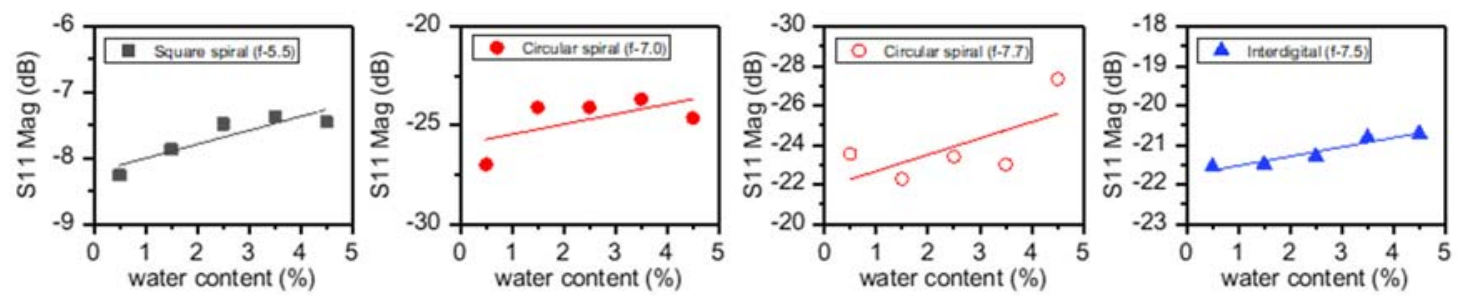

b
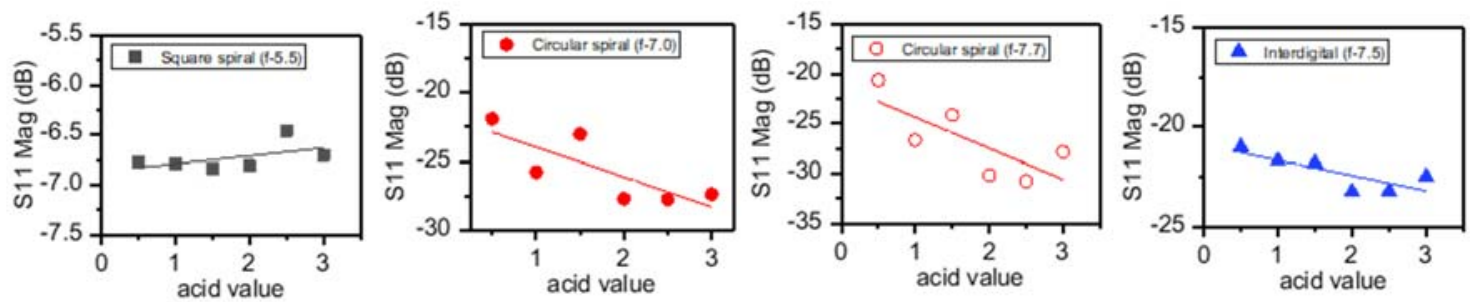

Figure S3, a, the reflection coefficient spectrum peak values of microstrip sensors based on squre spiral-based, circle spiral-based and interdigital structures for different water content

$(0.5 \%, 1.5 \%, 2.5 \%, 3.5 \%, 4.5 \%) ; \mathrm{b}$, the reflection coefficient spectrum peak values of microstrip sensors based on squre spiral-based, circle spiral-based and interdigital structures for different acid value $(0.5,1.0,1.5,2.0,2.5,3.0 \mathrm{mgKOH} / \mathrm{g})$

a

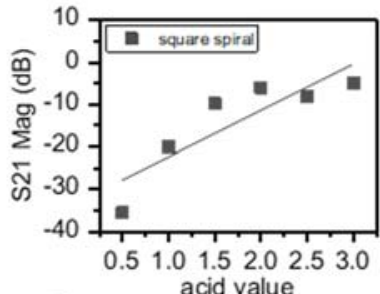

b

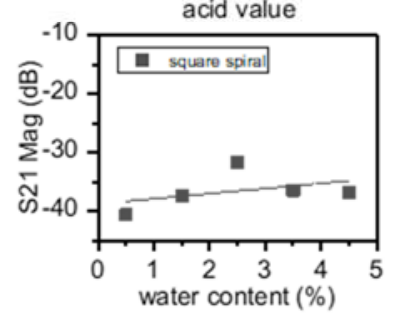

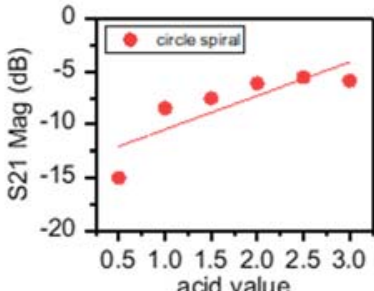

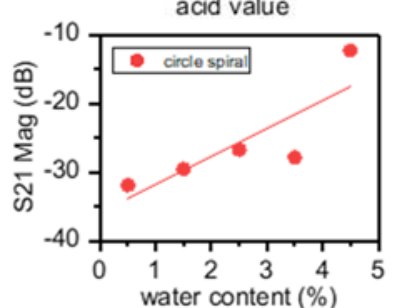

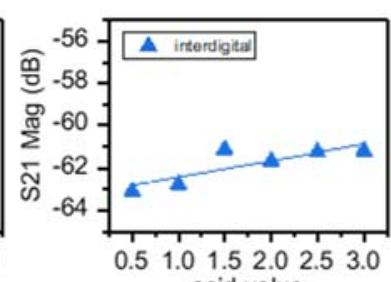

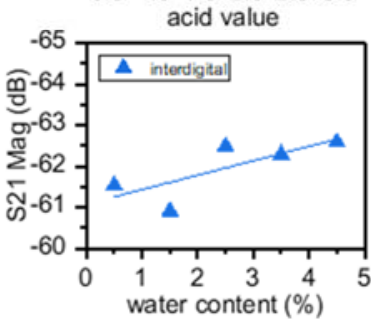

Figure S4, a, the transmission coefficient of microstrip sensors based on square spiral-based, circle spiral-based and interdigital structures for different acid value $(0.5,1.0,1.5,2.0,2.5,3.0$ $\mathrm{mgKOH} / \mathrm{g}$ ) at $10 \mathrm{MHz} ; \mathrm{b}$, the transmission coefficient of microstrip sensors based on square spiral-based, circle spiral-based and interdigital structures for different water content $(0.5 \%$, $1.5 \%, 2.5 \%, 3.5 \%, 4.5 \%$ ) at $10 \mathrm{MHz}$ 


\section{S5. Detection for oil sample containing the mixed acids}

Using the method in Surpporting Information S1, the oil sample A1 containing nitric acid is configured. Then, taking oleic acid as the representative of organic acid, the same method is used to prepare oil samples, A2. Oleic acid was added into the oil sample A1, and the oil sample A3, A4, A5 is configured. The acid values of A0 (fresh oil), A1, A2, A3, A4, A5 are 0.03, 0.15, $0.3,0.45,0.85,1.25 \mathrm{mgKOH} / \mathrm{g}$ respectively determined by standard titration method in accordance with ASTM D9745 ${ }^{5}$ Oil samples with different acid value were detected by the square spiral-based microstrip sensor, and the transmission coefficient of $100 \mathrm{kHz}-3 \mathrm{GHz}$ was recorded. As shown from Figure S5a, it can be seen that with the increase of acid value, transmission coefficient spectrum of sensor can be clearly distinguished. The transmission coefficient magnitude change in low frequency band has an appropriate linear relationship with acid value, although the oil samples are containing organic acids, inorganic acid or the mixture of inorganic and organic acids respectively (Figure S5b). This indicates that the sensor is effective for the detection of acid value in oil samples, including organic acid and inorganic acid.
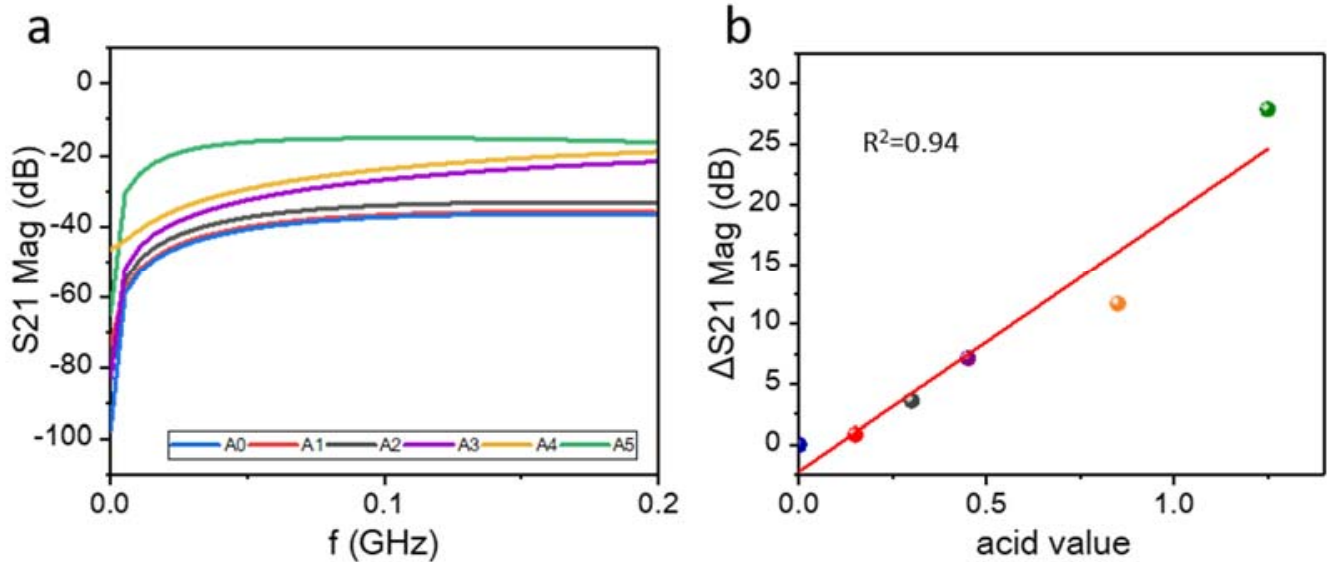

Figure S5. a, the magnitude of transmission coefficient with square spiral-based microstrip sensor for detecting oil sample (A0, A1, A2, A3, A4, A5); b, the transmission coefficient of square spiral-based microstrip sensor for different acid value in oil samples with mixed acids at $10 \mathrm{MHz}$. 


\section{S6. Sensitivities of microstrip sensors with different line widths}

The oil samples with different water contents were applied to the surface of the square spiralbased microstrip sensor, and the magnitude change of reflection coefficient increased with the increase of water concentration. Then the oil samples with different acid values were applied to the surface of the square spiral-based microstrip sensor, and the magnitude change of transmission coefficient increased with the increase of acid value. Figure S6 shows the response comparison of different line widths sensors.

a

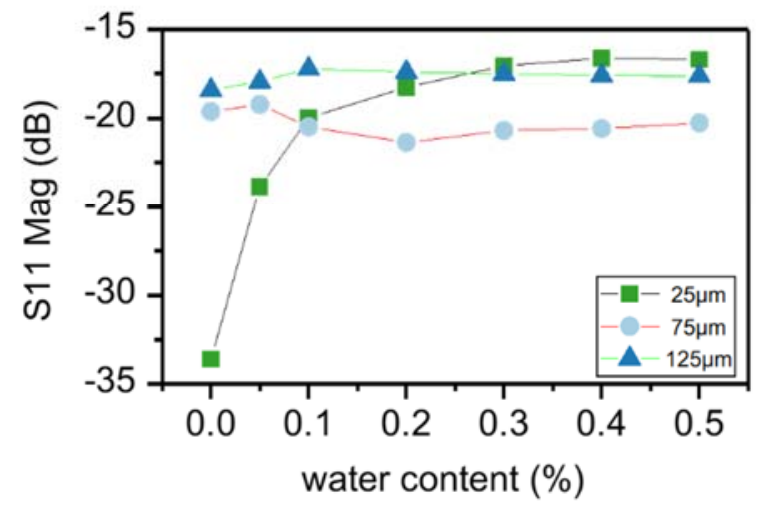

b

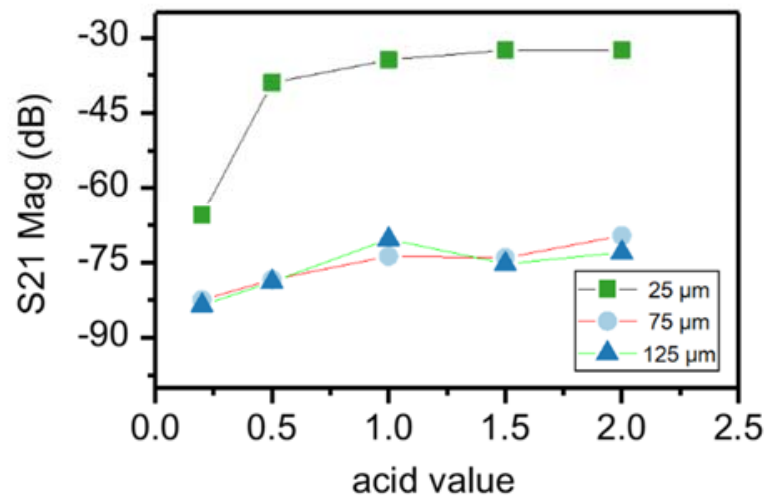

Figure S6. the response comparison of different line widths sensors for water content a); acid value b). 


\section{S7. Comparison of the proposed method with other oil detection methods}

Table S1 exhibits the detection performance comparison of the microstrip sensor with other oil quality detection methods. It shows that the proposed sensor can realize simultaneous detection of water content and acid value detection with smaller size. At the same time, compared with the reported methods, the proposed sensor has the equivalent or better performance in sensitivity linearity and detection range. 
Table S1. the performance comparison with other oil detection methods

\begin{tabular}{|c|c|c|c|c|c|c|c|c|c|c|c|c|}
\hline & & \multirow{2}{*}{$\begin{array}{l}\text { Sensor } \\
\text { size }\end{array}$} & \multicolumn{2}{|c|}{$\begin{array}{l}\text { Linear detection } \\
\text { range }\end{array}$} & \multicolumn{2}{|c|}{$\begin{array}{l}\text { Minimum response } \\
\text { concentration }\end{array}$} & \multicolumn{2}{|c|}{ Sensitivity } & \multicolumn{2}{|c|}{ Linearity } & \multirow[t]{2}{*}{ RSD } & \multirow{2}{*}{$\begin{array}{c}\text { Can WC and AV } \\
\text { be measured } \\
\text { simultaneously? }\end{array}$} \\
\hline & & & $\mathrm{WC}^{\mathrm{a}}$ & $A V^{b}$ & WC & $\mathrm{AV}$ & WC & $\mathrm{AV}$ & WC & $\mathrm{AV}$ & & \\
\hline \multirow{4}{*}{$\begin{array}{l}\text { Infrared } \\
\text { Spectroscopy }\end{array}$} & {$[6]$} & $\begin{array}{l}>10 \\
\mathrm{~cm}\end{array}$ & $\begin{array}{c}0.05 \%- \\
10 \%\end{array}$ & - & $0.05 \%$ & - & - & - & 0.9793 & - & - & No \\
\hline & {$[7]$} & $\begin{array}{l}>20 \\
\mathrm{~cm}\end{array}$ & $\begin{array}{c}3.51- \\
17.1 \%\end{array}$ & - & $3.51 \%$ & - & $0.085 \mathrm{Abs} / \%$ & - & 0.97 & - & - & No \\
\hline & {$[8]$} & $\begin{array}{l}>10 \\
\mathrm{~cm}\end{array}$ & - & $\begin{array}{l}0.2- \\
3.3\end{array}$ & - & 0.2 & - & - & - & 0.9929 & $\begin{array}{l}0.095 \\
\text { AV }\end{array}$ & No \\
\hline & {$[9]$} & $\begin{array}{l}>10 \\
\mathrm{~cm}\end{array}$ & - & $\begin{array}{c}0- \\
6.5 \%\end{array}$ & - & $1 \%$ & - & $\begin{array}{l}0.045 \\
\text { Abs } / \%\end{array}$ & - & 0.999 & $0.01 \%$ & No \\
\hline \multirow{4}{*}{$\begin{array}{l}\text { Electrochemical } \\
\text { method }\end{array}$} & [10] & $\begin{array}{l}>0.25 \\
\mathrm{~cm}^{2}\end{array}$ & $\begin{array}{c}0.05 \%- \\
0.18 \%\end{array}$ & - & $0.05 \%$ & - & $\begin{array}{c}5.539 \\
\left(\mathrm{~K} \Omega \cdot \mathrm{cm}^{-2}\right) \\
\left(\times 10^{2}\right) / \mathrm{WC} \%\end{array}$ & - & 0.995 & - & $0.67 \%$ & No \\
\hline & {$[11]$} & $\begin{array}{l}>3.5 \\
\mathrm{~cm}^{2}\end{array}$ & $8.5-45 \%$ & - & $8.50 \%$ & - & $\begin{array}{l}14.816 \mathrm{M} \Omega \\
/ \mathrm{WC} \%\end{array}$ & - & 0.9348 & - & - & No \\
\hline & [12] & $6 \mathrm{~mm}$ & - & $\begin{array}{l}0.53- \\
4.47\end{array}$ & - & 0.53 & - & $\begin{array}{c}6.63 \\
\mu \mathrm{S} / \mathrm{AV}\end{array}$ & - & 0.98 & - & No \\
\hline & [13] & $1 \mathrm{~cm}$ & - & $\begin{array}{l}0.49 \% \\
\text { to } \\
8.15 \%\end{array}$ & - & $0.19 \%$ & - & $\begin{array}{l}0.548 \\
\mathrm{nA} / \%\end{array}$ & - & 0.9985 & $2 \%$ & No \\
\hline This work & & $3 \mathrm{~mm}$ & $\begin{array}{c}0.05 \%- \\
0.5 \%\end{array}$ & $0.5-3$ & $0.05 \%$ & $<0.2$ & $\begin{array}{l}5.96 \mathrm{~dB} / \log \\
(\mathrm{WC} \%)\end{array}$ & $\begin{array}{r}2.38 \\
\mathrm{~dB} / \mathrm{log} \\
(\mathrm{AV}) \\
\end{array}$ & 0.994 & 0.925 & $0.23 \%$ & Yes \\
\hline
\end{tabular}

${ }^{a} \mathrm{WC}$ means water content. ${ }^{\mathrm{b}} \mathrm{AV}$ means acid value. 


\section{S8. Bending test}

The influence of bending disturbance was studied. The microwave spectrum of the sensor in the oil samples was tested under three bending states, including flat, bend $1\left(\alpha=63^{\circ}\right)$ and bend $2\left(\alpha=90^{\circ}\right)$. It can be seen that bending caused slight changes in the peak value of the reflection coefficient spectrum of the sensor (Fig. S7a). When the sensor is tested under three bending conditions respectively, the corresponding response of the sensor can clearly distinguish two oil samples containing low concentration water $(0.05 \%$ and $0.1 \%$ water content, $0.5 \mathrm{mg} \mathrm{KOH} / \mathrm{g}$ acid value). The response trends of three states are the same (Figure S7b). The response deviation of the sensor with the three bending states to the oil sample containing $0.05 \%$ water content is $2.88 \%$, and to the oil sample containing $0.1 \%$ water content is $5.88 \%$ (Fig. S7c). It shows that slight bending have not much influence on the response of the sensor. When the curvature is fixed, the sensor can distinguish low concentration of water. In actual situation, the curvature of the sensor should be fixed, and it is reasonable to believe that its detection performance will not be affected. 
a
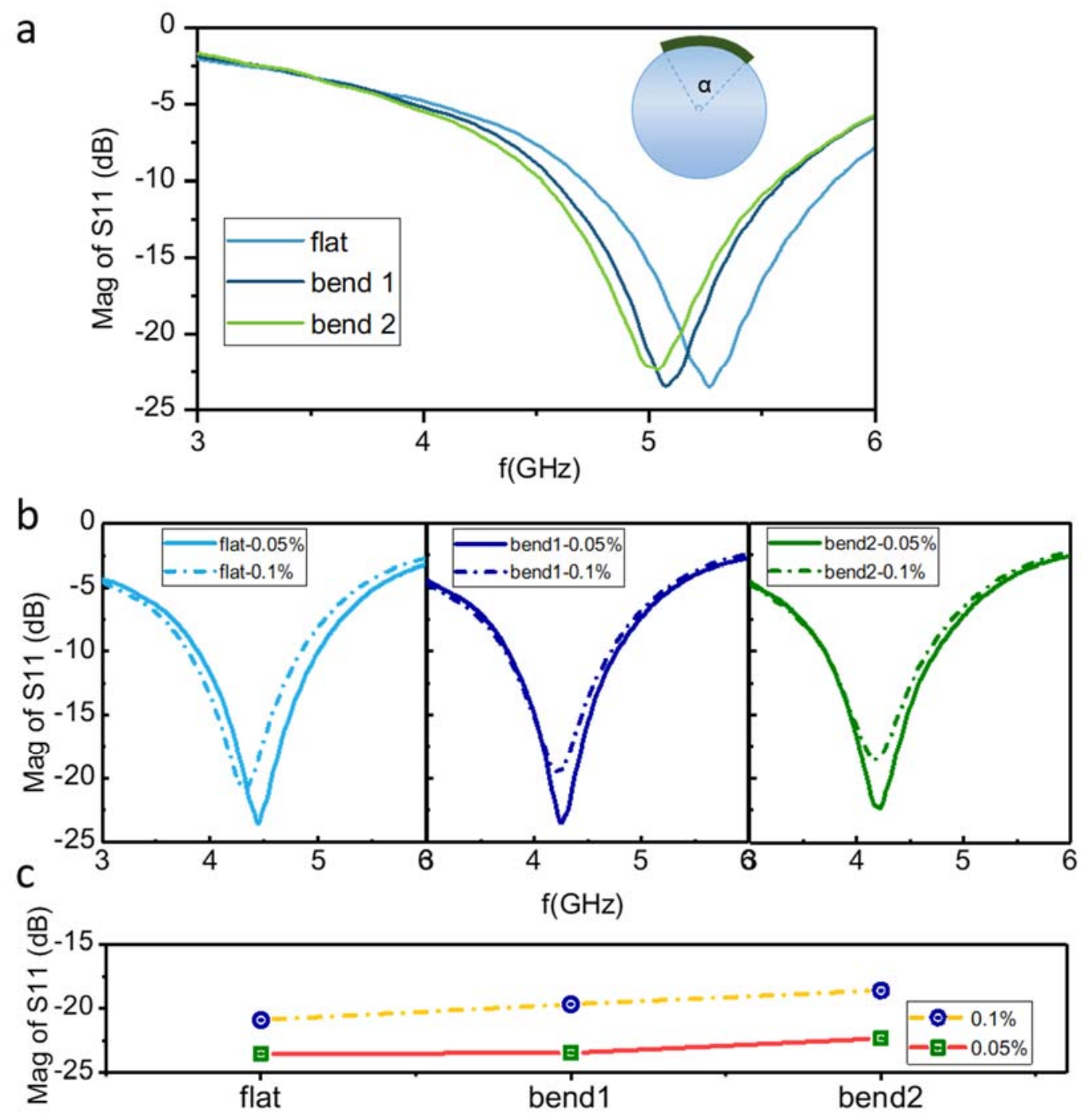

Figure S7. the response comparison of sensor with different states: flat, bend $1\left(\alpha=63^{\circ}\right)$, and bend $2\left(\alpha=90^{\circ}\right)$ a); reflection coefficient spectrum $b$ ) and peak value c) of the sensor to two kinds of oil samples with low concentration of water content $(0.05 \%, 0.1 \%)$. 


\section{S9. Long-time stability experiment}

Figure S8 plots the peak value of reflection coefficient spectrum in real time up to 10 hours. The response of the sensor is stable when it is tested in the oil samples containing $0.4 \%$ water content. The response deviation within 10 hours for $0.4 \%$ water content of oil sample is less than $1.00 \%$. The experimental results show that the sensor has a suitable stability, and has the potential for on-site real-time monitoring.

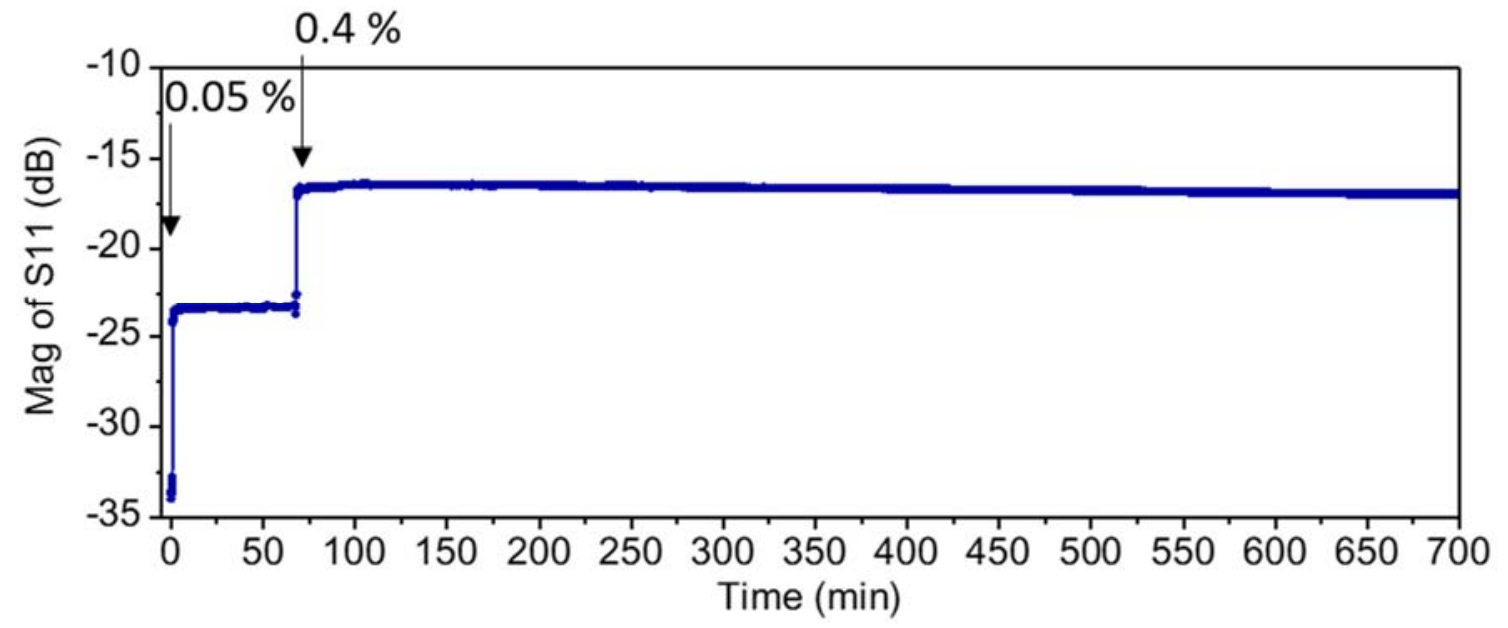

Figure S8. Long-time stability experiment: the square spiral-based microstrip sensor was tested in the in the oil samples containing $0.4 \%$ water content for 10 hours. 


\section{REFERENCES}

(1) Soleimani, M.; Sophocleous, M.; Glanc, M.; Atkinson, J.; Wang, L.; Wood, R. J. K.; Taylor, R. I., Engine oil acidity detection using solid state ion selective electrodes. Tribology International 2013, 65, 48-56.

(2) Mamishev, A. V.; Sundara-Rajan, K.; Fumin, Y.; Yanqing, D.; Zahn, M., Interdigital sensors and transducers. Proceedings of the IEEE 2004, 92 (5), 808-845.

(3) Alam, M. N.; Bhuiyan, R. H.; Dougal, R. A.; Ali, M., Concrete Moisture Content Measurement Using Interdigitated Near-Field Sensors. IEEE Sensors Journal 2010, 10 (7), 1243-1248.

(4) Gevorgian, S.; Berg, H.; Jacobsson, H.; Lewin, T., Application notes - basic parameters of coplanar-strip waveguides on multilayer dielectric/semiconductor substrates, Part 1: high permittivity superstrates. IEEE Microwave Magazine 2003, 4 (2), 60-70.

(5) de Godoy, L. A. F.; Pedroso, M. P.; Ferreira, E. C.; Augusto, F.; Poppi, R. J., Prediction of the physicochemical properties of gasoline by comprehensive two-dimensional gas chromatography and multivariate data processing. Journal of Chromatography A 2011, 1218 (12), 1663-1667.

(6) Mirghani, M. E. S.; Kabbashi, N. A.; Alam, M. Z.; Qudsieh, I. Y.; Alkatib, M. a. F. R., Rapid Method for the Determination of Moisture Content in Biodiesel Using FTIR Spectroscopy. Journal of the American Oil Chemists' Society 2011, 88 (12), 1897-1904.

(7) Borges, G. R.; Farias, G. B.; Braz, T. M.; Santos, L. M.; Amaral, M. J.; Fortuny, M.; Franceschi, E.; Dariva, C.; Santos, A. F., Use of near infrared for evaluation of droplet size distribution and water content in water-in-crude oil emulsions in pressurized pipeline. Fuel 2015, 147, 43-52.

(8) Jiang, X.; Li, S.; Xiang, G.; Li, Q.; Fan, L.; He, L.; Gu, K., Determination of the acid values of edible oils via FTIR spectroscopy based on the $\mathrm{OH}$ stretching band. Food Chemistry 2016, 212, 585-589.

(9) Aryee, A. N. A.; van de Voort, F. R.; Simpson, B. K., FTIR determination of free fatty acids in fish oils intended for biodiesel production. Process Biochemistry 2009, 44 (4), 401405.

(10) Delfino, J. R.; Pereira, T. C.; Costa Viegas, H. D.; Marques, E. P.; Pupim Ferreira, A. A.; Zhang, L.; Zhang, J.; Brandes Marques, A. L., A simple and fast method to determine water content in biodiesel by electrochemical impedance spectroscopy. Talanta 2018, 179, 753 759.

(11) Perini, N.; Prado, A. R.; Sad, C. M. S.; Castro, E. V. R.; Freitas, M. B. J. G., Electrochemical impedance spectroscopy for in situ petroleum analysis and water-in-oil emulsion characterization. Fuel 2012, 91 (1), 224-228.

(12) Grossi, M.; Di Lecce, G.; Gallina Toschi, T.; Riccò, B., A novel electrochemical method for olive oil acidity determination. Microelectronics Journal 2014, 45 (12), 1701-1707. (13) Baldo, M. A.; Oliveri, P.; Simonetti, R.; Daniele, S., A novel electroanalytical approach based on the use of a room temperature ionic liquid for the determination of olive oil acidity. Talanta 2016, 161, 881-887. 